\section{Hereinspaziert zum Tag des offenen Denkmals}

Super Sommerwetter begleitete den Tag des offenen Denkmals 2016 in Remscheid Lennep, dem Geburtsort von Wilhelm Conrad Röntgen. Zum zweiten Mal nahm das Geburtshaus an diesem Denkmaltag teil. Das Röntgen-Museum mit seinem Leiter Dr. Uwe Busch sowie die Deutsche Röntgengesellschaft luden am 11. September 2016 nach Lennep, damit Groß und Klein das Geburtshaus von Röntgen bestaunen und sich gleichzeitig davon überzeugen konnten, wie gut die Bau- und Renovierungsarbeiten am Haus vorangehen.

Etwa 60 Besucher zog es zum Geburtshaus. Darunter auch die Familie von Prof. Gerald Antoch, DRG-Mitglied und Leiter des Instituts für Diagnostische und Interventionelle Radiologie am Universitätsklinikum Düsseldorf, und eine Delegation chinesischer Ingenieure. Gerösteter Röntgenkaffee und X-Kekse lockten die Interessierten ins Haus. „Das kam sehr gut an, und wir haben uns über das große Interesse sehr gefreut“, erklärt Dr. Uwe Busch. Im Obergeschoss des Geburtshauses hatte man für Kinder und Erwachsene einen Bereich so hergerichtet, dass dort mit Lehmsteinen gemauert werden konnte. Ein großer Spaß für die kleinen Gäste! „Eine halbe Wand ist so im Laufe des Tages fertiggestellt worden, und sie soll wohl auch bleiben“, so Dr. Busch.

Nach wie vor fasziniert die Besucher die Konstruktion alter bergischer Häuser. Besucher bekräftigten, dass man sehr gespannt auf die Fertigstellung und die spätere Nutzung sei. „Ein Juwel für Lennep!“ ließen mehrere Besucher verlauten.
Die Geburtshaus Stiftung freut sich insbesondere über die am 11.09. eingegangenen Spenden. Herzlichen Dank dafür! Auf der Webseite des Geburtshauses (www. roentgen-geburtshaus.de) erfahren Sie alles über den Werdegang des Hauses - dieses wichtigen Schatzes der Radiologie.

\section{Nachgefragt bei einem Düsseldorfer Besucher: Professor Gerald Antoch $\nabla$} uns über Ihren Besuch in Röntgens Geburtshaus! Sagen Sie, ist Lennep eine Reise wert?

Lennep bietet mit dem Geburtshaus und dem Röntgenmuseum zwei Highlights, die die kleine Stadt im Bergischen Land zu einem „Muss“ für Radiologen und MTRA machen. Das Röntgen-Museum bietet zudem durch die interaktiv aufgebaute Ausstellung die Möglichkeit, auch Kindern die Radiologie spielend und anschaulich näherzubringen. Wenn alle Museen so auf-
Herr Professor Antoch, wir freuen

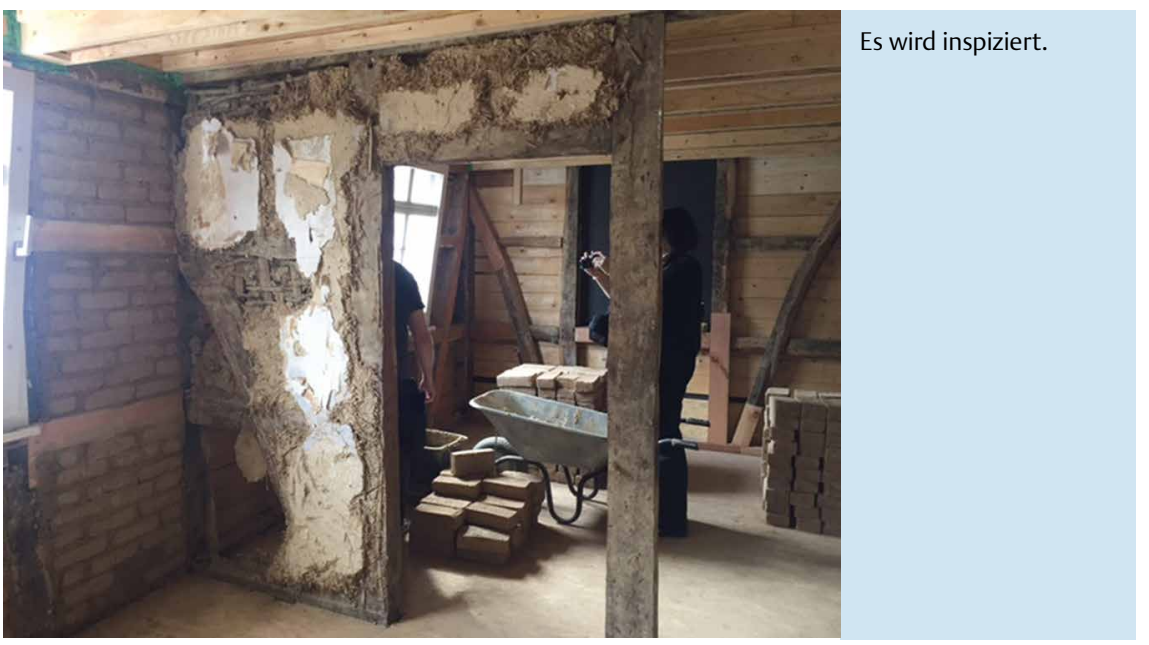

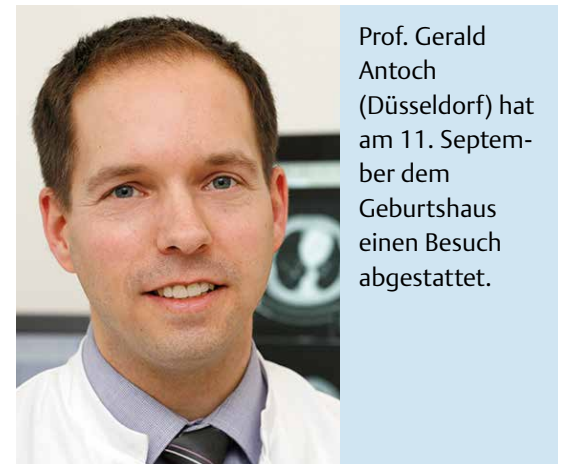

gebaut wären, würden wir unsere Kinder wahrscheinlich häufiger von einem Museumsbesuch überzeugen können.

\section{Was hat Sie am Tag des offenen Denkmals im Röntgen Geburtshaus} am meisten beeindruckt?

Besonders beeindruckt hat uns, dass trotz der aufwändigen Sanierungsmaßnahmen der Charakter des alten Hauses erhalten bleibt. Die Wände werden zwischen dem Fachwerk nicht ausgemauert oder mit Platten verkleidet, sondern altersentsprechend mit Lehmziegeln erstellt. Das ist aufwändig und arbeitsintensiv, mit Blick auf die Bedeutung des Hauses aber die richtige Entscheidung. Welche Fachgesellschaft kann schon von sich sagen, dass Sie das Geburtshaus ihres Gründers besitzt!

\section{? Warum haben Sie sich für eine Spende fürs Geburtshaus entschie- den?}

Die Radiologie basiert ganz wesentlich auf der Entdeckung von Wilhelm Conrad Röntgen. Einfach gesagt: Ohne Herrn Röntgen würden wir heute alle etwas anderes beruflich machen. Und auch wenn ich nicht sagen kann, was das wohl alternativ sein würde, es wäre bestimmt nicht so faszinierend wie die Radiologie. Die Sanierung und der Erhalt des Röntgen Geburtshauses ist meiner Familie und mir daher ein wichtiges Anliegen, für das wir gerne spenden. 

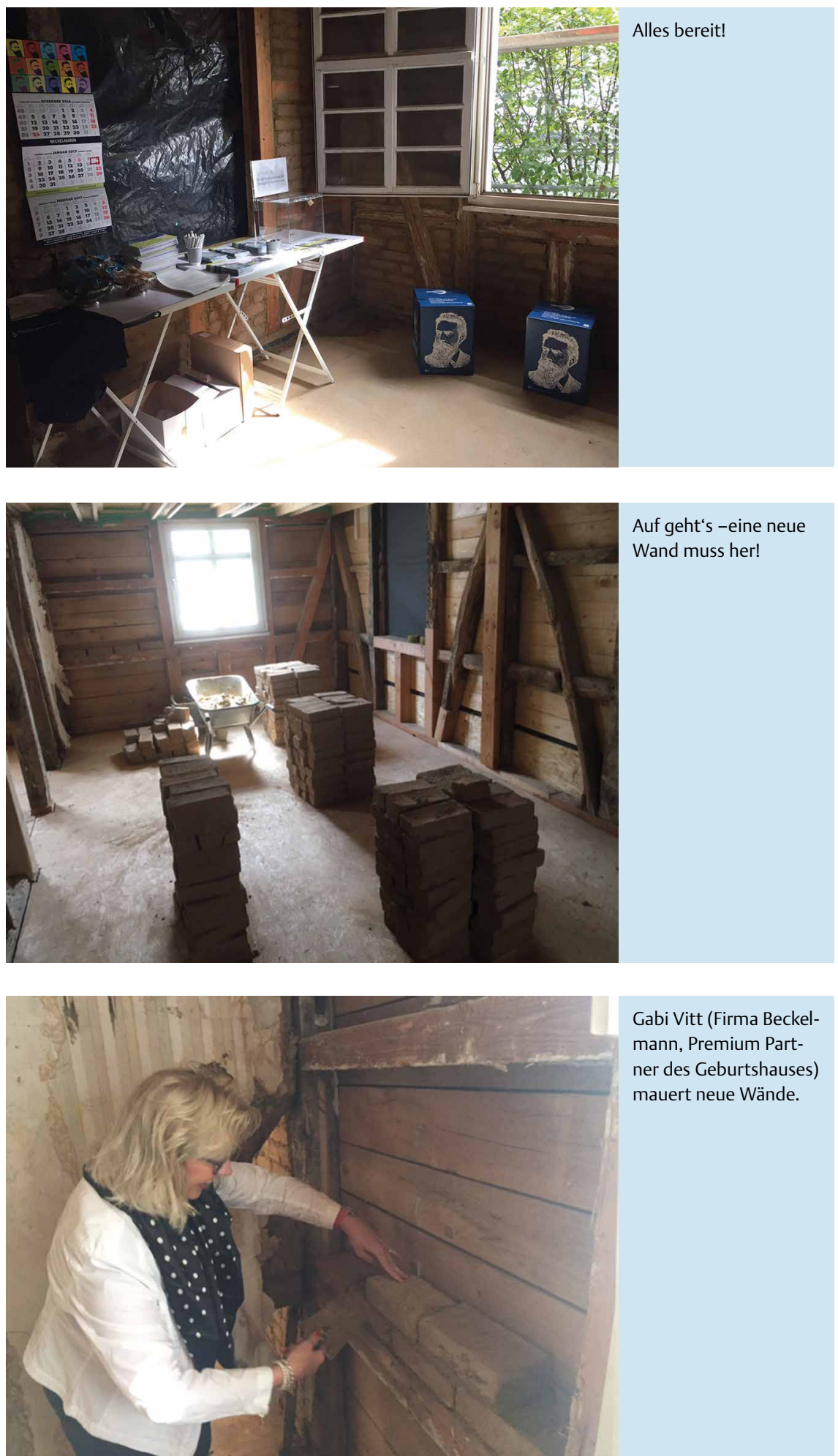

Alles bereit!

Auf geht's -eine neue

Wand muss her!

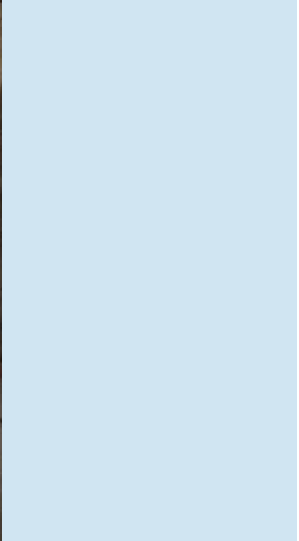

Gabi Vitt (Firma Beckelner des Geburtshauses) mauert neue Wände.

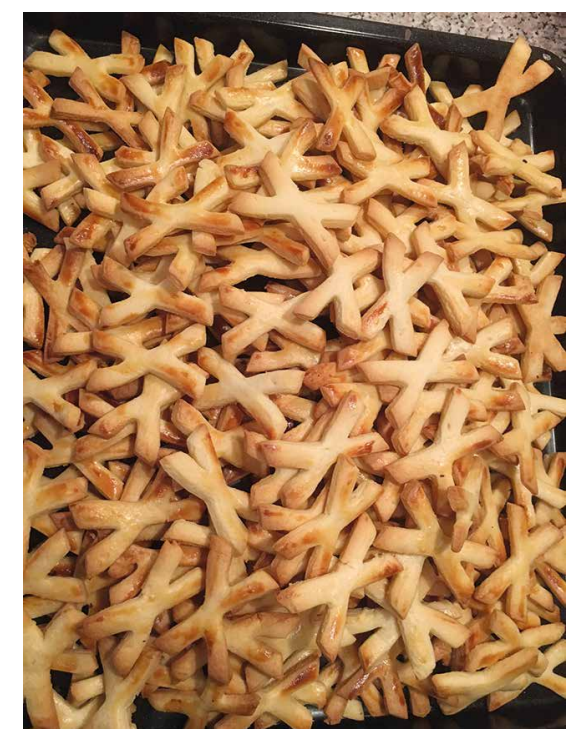

Greifen Sie zu - X-Kekse. 